\title{
Population Dynamics and Clonal Comparisons of Cowpea Aphid (Homoptera: Aphididae) on Resistant and Susceptible Cowpea Cultivars
}

\author{
I. BILLY ANNAN, ${ }^{1}$ WARD M. TINGEY, AND GEORGE A. SCHAEFERS ${ }^{2}$ \\ Department of Entomology, Cornell University, Insectary, Tower Road, \\ Ithaca, NY 14853-2604
}

\begin{abstract}
Environ. Entomol. 26(2): 250-255 (1997)
ABSTRACT Survivorship, growth, and reproductive performance of cowpea aphid, Aphis craccivora Koch, were studied on whole plants and excised plant tissues of aphid-resistant ('ICV-12') and aphid-susceptible ('ICV-1') cultivars of cowpea, Vigna unguiculata (L.) Walp. In a greenhouse study, clonal populations derived from individuals that were originally collected from 5 different locations were studied on plants of the 2 cultivars to assess possible development of aphid biotypes. In the laboratory, performance of 1 clone was studied on excised leaves, flowers, and pods to assess tissue localization and effect of injury on ICV-12 resistance. Aphid life table parameters measured included survivorship, reproductive period, intrinsic rate of increase, net rate of reproduction, number of generations and generation time. Aphid reproductive performance and life table parameters were significantly reduced on seedlings and excised tissues of ICV-12 plants compared with ICV-1. Survivorship, intrinsic rate of increase and net rate of reproduction of populations were most adversely affected. Antibiosis appeared to contribute to aphid resistance in ICV-12. Effects of excised ICV-12 foliage were stronger than those of flowers or pods. Thus, the resistant factor in ICV-12 apparently was based in seedling foliage. However, there were no differences among excised tissues of ICV-1. Trends in the results indicated that there was no variability among the different populations in their demographic statistics on each cultivar. Thus, there did not seem to be biotype development or breakdown of ICV-12 resistance in any of the A. craccivora populations.
\end{abstract}

KEY WORDS Aphis craccivora, population dynamics, Vigna unguiculata, antibiosis, intrinsic rate of increase, aphid resistance

COWPEA APHID, Aphis craccivora Koch, is an economic pest of cowpea, peanuts, and other legumes worldwide. It causes serious direct damage to cowpeas through their feeding and draining of plant sap, and is also an important vector of several viruses (Singh et al. 1978, Singh and Rachie 1985). Studies of the effects of host plant resistance and crop phenology on aphid behavior, population dynamics, and aphid-plant interactions have been well-researched (Cartier 1960; Messina et al. 1985; Ofuya 1989, 1993; Annan 1992).

Aphid-plant interactions may be affected by damage resulting from injury to plants through agencies like insect feeding, poor nutrition, water stress, or adverse environmental factors. Tingey (1986) mentioned that injury to plants may alter plant resistance such that differences between resistant and susceptible cultivars may be diminished. According to Cartier (1963), pea plants with

\footnotetext{
'E.I. DuPont de Nemours, Agricultural Products, Stine-Haskell Research Center, Elkton Road, P.O. Box 30, Newark, DE 19714-0030.

${ }^{2}$ Comell University, New York State Agricultural Experiment Station, Department of Entomology, Box 462, Geneva, NY $14456-0462$.
}

yellowish green leaves were highly colonized by pea aphid while deep green leaves were least colonized. Thus, diseased or senescing pea plants with yellowed leaves may be preferred by aphids for infestations or colonization.

Different aphid populations or biotypes often interact differentially with varieties of host plants. Such interactions may result in an apparent reduction or even loss of plant resistance in resistant crop lines or an alteration of the insect bionomics. For instance, Caillaud et al. (1995a) reported differences among clones of Sitobion avenae (F.) in their intrinsic rate of natural increase and nymphal development time on resistant and susceptible wheat accessions. Also, Niassy et al. (1987) reported variable responses in fecundity and honeydew production of biotypes B and E of Schizaphis graminum (Rondani), on resistant and susceptible wheat genotypes.

Cowpea germplasm used in the studies were aphid-resistant ICV-12 and aphid-susceptible ICV-1, registered and released by the ICIPE in Kenya. ICV-1 is an early-maturing single-plant selection from land races of eastern Kenya. ICV-12 
was developed from ICV-1 through induced mutations with $\gamma$-irradiation (Pathak and Olela 1986). Both cultivars have similar morphological habits and phenological traits but differ mainly in their resistance or susceptibility to $A$. craccivora. Aphid resistance in ICV-12 is governed by a single dominant gene (Pathak 1988). Givovich et al. (1988) and Firempong (1988) determined that both antibiosis and antixenosis were important mechanisms of ICV-12 resistance. However, those authors did not elucidate the tissue location of the resistant factors. Also, although their investigations were done independently, both apparently used aphids from the same local population. Thus, they could not assess responses of different aphid populations or the possible reduction or loss of aphid resistance in ICV-12.

This work was conducted as part of an overall research effort to characterize mechanisms of aphid resistance in the selected cowpea cultivars and the population dynamics of $A$. craccivora on those cultivars. Specific objectives were to compare (1) aphid resistance in whole plants of ICV-12 on population parameters of 5 different clones to assess potential development of biotypes that would overcome plant resistance, and (2) levels of expression of resistance among various excised plant tissues of ICV-12 to determine tissue localization of aphid resistance factors, and also assess the effect of wounding by excision on resistance expression.

\section{Materials and Methods}

Laboratory and greenhouse studies of aphid life tables were conducted at Mbita Point Field Station (MPFS) of the International Center of Insect Physiology and Ecology (ICIPE) in Kenya. The studies were based on horizontal or age-specific life tables of a real cohort generation in a stationary population (Southwood 1978).

Source of Plant Material. Seeds of ICV-12 and ICV-1 were supplied by J. C. Olela and R. S. Pathak at ICIPE. A susceptible cowpea cultivar, VITA-7, was used in rearing aphid populations. ICV-12 is widely cultivated in the area where MPFS is situated, but not in other parts of Kenya where A. craccivora also is a significant pest.

Greenhouse Life Table Studies of Different Clonal Populations on Seedling Plants. Aphid Material. Test aphids were young adult apterae of similar age, that were progenies of maternal individuals that were collected at 5 specified populations.

Different populations were used in this work to ascertain purported development of biotypes on different cowpeas at some locations in Kenya. This was considered important because of its implications on the potential breakdown of aphid resistance in ICV-12 and the consequent effects on crop losses in Kenya.
Aphids from the MPFS population consisted of clones that were progenies of a single matemal individual collected from a plant in a small test plot of an aphid-resistant cowpea cultivar, TVu-310, at MPFS in February 1990. The station is situated on the shores of Lake Victoria in the Suba district of Nyanza Province in western Kenya, at an elevation of $\approx 1000 \mathrm{~m}$.

The Mtwapa population was cultured from an aphid that was collected from an uncultivated groundnut plant in a sorghum field at Mtwapa near Mombasa in May 1990. The source plot was 900 $\mathrm{km}$ southeast of MPFS, with a coastal savanna climate.

Populations from Oyugis and Embu also were reared from single individuals that were originally collected from cowpea plants. Collection and initial rearing of cohorts for both populations were done in July 1990 . The Oyugis population was obtained from an aphid that was collected from a plant of an aphid-resistant cowpea cultivar (ICV10) in a field located near Oyugis in Homa Bay district of Kenya. The field source was $\approx 150 \mathrm{~km}$ east of MPFS. The Embu population was reared from an individual that was collected from a field of cowpea landraces at Embu in the Central Province of Kenya. The field was located at an elevation of $\approx 1,500 \mathrm{~m}$ and $450 \mathrm{~km}$ due east of MPFS. The landrace was the same as that from which ICV-10 was reportedly developed as a single plant selection (Pathak and Olela 1986).

Finally, the Ungoye population was established from the progeny of an aphid that was selected from a small colony on a single plant of ICV-12 cowpea at the ICIPE Farm at Ungoye, also in the Suba district of Nyanza Province in western Kenya. The farm is located $\approx 40 \mathrm{~km}$ southwest of MPFS and has similar elevation and climate.

Because collections of maternal individuals of the 5 test aphid populations were done at different times from plants in different locations, and rearing of cohort generations were initiated at different times the resultant populations were assumed to be distinct and nonoverlapping. Each population was carefully maintained in a separate greenhouse under similar environmental conditions.

Experimental Design. The study was conducted between early October to mid-December 1990 using 5 different clonal populations of $A$. craccivora. The primary objective was to detect differential effects of ICV-12 resistance on life table parameters of selected clonal aphid populations.

The study was set up in a completely randomized design for each of the 5 aphid populations from MPFS, Mtwapa, Oyugis, Embu, and Ungoye, respectively. There were 15 replicates per cultivar treatment for each aphid population. Studies were conducted on seedlings of ICV-12 and ICV-1 under greenhouse conditions of $24 \pm 4^{\circ} \mathrm{C}, 40-90 \%$ $\mathrm{RH}$, and a photoperiod of 14:10 (L:D) h. Test plants of the 2 cultivars also were propagated under similar conditions. Seedlings at the 2nd-trifo- 
liate stage were used in the whole plant studies because that is the growth stage at which the maximum expression of field resistance to cowpea aphid in ICV-12 is observed (MacFoy and Dabrowski 1984, Pathak 1988, Annan 1992, Annan et al. 1994).

Experiments also were conducted in a different greenhouse from where the rearing colonies were maintained. In each experiment, a cohort generation of 20 aphids was established on young shoots of plants. Individual plants were kept in cages measuring $30 \mathrm{~cm}$ by $30 \mathrm{~cm}$ by $60 \mathrm{~cm}$, and constructed of 32-mesh No-See-Um polyester supported on aluminum cage frames. Each cage contained 1 replicate (aphid colony on a plant). Test plants were replaced weekly to avoid senescence or wilting of plants and to prevent any possible adverse effects on test aphid colonies. Infestations of test aphids were restricted on leaves of seedlings.

Laboratory Life Table Studies of 1 Clonal Population on Excised Plant Tissues. Aphid Material. Because of similarities in responses of the different aphid populations in the greenhouse studies, only the MPFS clone was used in the laboratory study, which was conducted in FebruaryMarch 1991. Apterous adults were collected from the same MPFS clone used in the greenhouse studies, and were restricted on seedling leaves or flowers or pods. Tissues that were used as test substrates were carefully excised at their stalks from potted greenhouse plants grown. The excised stalks were quickly placed in a small flask filled with water. Each preparation was kept in a cage made of polyester organdy and lined with pads of moistened laboratory towels to maintain humidity. To minimize effects of deteriorating of substrates, test colonies were transferred to fresh supplies of the respective plant tissues of both cultivars after every 2 d.

In all studies, adult aphids were placed on plants for $24 \mathrm{~h}$ for larviposition, after which they were removed. Offspring of similar age $( \pm 1 \mathrm{~d})$ were then used as the cohort population. Cohort individuals were carefully monitored daily to determine time taken to reach adult stage, and thus to estimate time to the start of reproduction, reproductive period, and generation time. After the cohort population started reproduction, their offspring were counted and removed daily. Data were recorded until cohort individuals died or colonies collapsed. In studies with the Ungoye population, the duration of reproductive period was not recorded.

Experimental Design. The main objective of this study was to determine tissue localization of aphid resistance, and effects of injury by the excision of plant tissues, on the level of expression of ICV-12 resistance and thus on aphid population dynamics. Experimental conditions were standardized at 26 $\pm 1^{\circ} \mathrm{C}, 40-80 \% \mathrm{RH}$, and a photoperiod of $16: 8$ (L: D) h. Continuous illumination at $40 \mu \mathrm{Em}^{-2} \mathrm{~s}^{-1}$ intensity was supplied by $40-\mathrm{W}$ Tezla Z Daylight flu- orescent lamps (Tezla, Czech Republic). One experiment was conducted from mid-September to late October 1990 and was set up as split plots in a randomized complete block. Main plots corresponded to the cowpea cultivars ICV-12 and ICV-1, whereas the split plots consisted of the plant tissue substrates (excised seedling leaves, flowers, and pods on their stalks.) There were 25 replicates per cultivar and excised tissue combinations.

Parameters and Statistical Analyses. Data recorded in both studies were mean estimates of survivorship of cohort individuals to adult stage $\left(l_{x}\right)$, reproductive period (days) per generation, intrinsic rate of natural increase $\left(r_{m}\right)$, net rate of reproduction $\left(R_{0}\right)$, number of generations, and generation time (T) (Birch 1948). The $r_{\mathrm{m}}$ was calculated as $\log _{e} R_{o} T$, and $R_{o}$ was estimated as $\Sigma l_{x} m_{x}$ (Andrewartha and Birch 1954), where $m_{\mathrm{x}}$ is the sum of age-specific fecundity or the number of nymphs produced per aphid per unit time.

Data were analyzed using analysis of variance (ANOVA) (SAS Institute 1988). Estimates of $l_{\mathrm{x}}$ covered a wide range of values and were therefore subjected to arcsine transformation (Snedecor and Cochran 1980). In the greenhouse study, data were analyzed by population source, comparing effects of ICV-12 and ICV-1. Specific effects of cultivar selection on aphid life table parameters were determined using the Student $t$-test $(P<0.05)$ for the greenhouse experiment on whole plants, and $95 \%$ CI for the laboratory experiment on excised plant tissues.

\section{Results}

Significant differences $(P \leq 0.05)$ were observed between ICV-12 and ICV-1 cowpeas for survivorship and reproductive performance of cowpea aphid on seedling plants and excised plant tissues (Table 1; Fig. 1).

Greenhouse Life Table Studies of Different Clonal Populations on Seedling Plants. Student $t$-test comparisons indicated that relative to ICV-1, seedlings of ICV-12 produced significant ( $P \leq$ 0.05 ) adverse effects on all parameters of aphid life tables and reproductive performance in each population (Table 1). However, no significant differences were detected between the 2 cultivars for reproduction period in the Oyugis population and number of generations in the Mtwapa population. Differences in $l_{\mathrm{x}}, \mathrm{r}_{\mathrm{m}}$ and $R_{\mathrm{o}}$ on the 2 cultivars were highly significant $(P \leq 0.001, d f=1, n=15)$ and were consistent for all populations.

Laboratory Life Table Studies of 1 Clonal Population on Excised Plant Tissues. Trends in the results of this experiment were similar to those observed in the previous experiment on whole plants. Except for reproduction period for all excised tissues and generation time for pods, all tissues of $\mathrm{ICV}-12$ produced significant adverse effects 
Table 1. Mean life-table statistics of 5 different clonal populations of cowpea aphid on plants of aphid-resistant (ICV-12) and aphid-susceptible (ICV-1) cowpea cultivars under greenhouse conditions

\begin{tabular}{|c|c|c|c|c|c|c|c|}
\hline $\begin{array}{l}\text { Source of clonal } \\
\text { population }\end{array}$ & $\begin{array}{c}\text { Test } \\
\text { cultivar }\end{array}$ & $l_{x}^{a}$ & $\begin{array}{l}\text { Reproduction } \\
\text { period, d }\end{array}$ & $r_{m}$ & $R_{0}$ & $\begin{array}{l}\text { No. } \\
\text { generations }\end{array}$ & $T, \mathrm{~d}$ \\
\hline \multirow[t]{2}{*}{ ICIPE-MPFS } & ICV-12 & $0.18^{* * *}$ & $2.9 * * *$ & $0.05^{* * *}$ & $2.5 * * *$ & $1.3^{* *}$ & $18.3^{*}$ \\
\hline & ICV-I & 0.80 & 6.1 & 0.22 & 22.6 & 2.4 & 14.2 \\
\hline \multirow[t]{2}{*}{ Mtwapi } & ICV-12 & $0.11^{* * *}$ & $4.4^{*}$ & $0.08 * * *$ & $3.2^{* * *}$ & $1.1 * *$ & $14.5^{*}$ \\
\hline & ICV-1 & 0.87 & 4.9 & 0.34 & 39.7 & 1.2 & 10.9 \\
\hline \multirow[t]{2}{*}{ Oyugis } & ICV.12 & $0.27^{* * *}$ & 4.2 & $0.06 * * *$ & $3.7 * * *$ & $1.0^{* *}$ & $22.3 * * *$ \\
\hline & ICV-I & 0.71 & 4.1 & 0.29 & 35.3 & 2.9 & 11.9 \\
\hline \multirow[t]{2}{*}{ Embu } & ICV-12 & $0.16^{* *}$ & $5.3 * *$ & $0.08^{* * *}$ & $3.3^{* * *}$ & $1.5^{*}$ & $17.1^{* *}$ \\
\hline & ICV-I & 0.79 & 7.2 & 0.30 & 24.0 & 2.0 & 10.6 \\
\hline \multirow[t]{2}{*}{ Ungoye } & ICV-12 & $0.23^{* * *}$ & - & $0.03^{* * *}$ & $2.2 * * *$ & $0.8^{* * *}$ & $26.3^{* * *}$ \\
\hline & ICV-1 & 0.72 & - & 0.21 & 36.8 & 3.5 & 17.2 \\
\hline
\end{tabular}

Means within a column for each source location are significantly different. ***, $P \leq 0.001 ; * *, P \leq 0.01$;,$P \leq 0.05$ (Student $t$. test). $T$, time.

$a$ Proportion of cohort individuals surviving to adult stage; arcsine transformed data.

on aphid life table parameters compared with ICV-1 (Fig. 1).

Two-way ANOVA indicated significant interactions between cultivar and excised plant tissues for aphid survivorship $(F=5.53 ; \mathrm{df}=2,150 ; P<$ $0.001)$, intrinsic rate of increase $(F=13.03 ; \mathrm{df}=$ $2,150 ; P<0.001)$, number of generations $(F=$ 5.07; $\mathrm{df}=2,144 ; P<0.001$ ), and generation time $(F=32.4 ; \mathrm{df}=2,150 ; P<0.001)$. Analyses for specific effects using $95 \%$ CIs indicated that, compared with similar treatments of ICV-1, excised tissues of ICV-12 produced consistent adverse effects on aphid survivorship, reproductive performance, and population growth parameters (Fig 1).

In general, excised foliage of ICV-12 seedlings also adversely affected aphid survivorship and reproductive performance more than flowers or pods. Exceptions to that trend included the mean reproduction period per generation and the mean number of generations per cohort population (Fig. 1; Table 1).

There were no significant differences between excised flowers and pods of ICV-12 except for $l_{x}$, which was higher on excised pods than on flowers. Within ICV-1, there were no significant differences in effects of excised plant tissues for all aphid life table parameters (Fig. 1).

\section{Discussion}

Results of this work indicated that seedlings of the aphid-resistant cultivar ICV-12 produced significant deleterious effects on survivorship and reproductive performance of $A$. craccivora, compared with the aphid-susceptible cultivar, ICV-1. Also, there was no variability in trends of the responses of the 5 different aphid populations to ICV-12 resistance. Interestingly, 2 of the populations were developed from sources where ICV-12 is widely deployed in the field, whereas at the other 3 source locations, the cultivar is not commonly cultivated.

Adverse effects of ICV-12 plants and excised plant parts on aphid life table parameters in this work suggest that antibiosis (Painter 1951) is a goveming mechanism of cowpea aphid resistance in that cultivar. Complementary studies revealed severe disruption of the aphid feeding behavior on whole plants, excised plant parts, and ethyl acetate extracts of leaves of ICV-12 seedlings (Annan 1992, Annan et al. 1996). Therefore, results of this work and the other studies indicate that both antibiosis and antixenosis are mechanisms of $A$. craccivora resistance in ICV-12. This is consistent with findings in similar studies with ICV-12 and other resistant cowpea cultivars (Givovich et al. 1988; Firempong 1988; Ofuya 1988a, b). Also, it is obvious from the laboratory study in this work and the aforementioned complementary studies that the factor that is responsible for ICV-12 resistance against the aphid is based in phloem sieve elements in seedling foliage.

Because the aphid clonal populations used in this work were considered to be distinct from each other, the lack of variability in the performance responses of those populations on the test cultivars signified a high level of aphid resistance in ICV-12 and susceptibility in ICV-1 to A craccivora. It also indicated that the different populations were similar in their life table responses. From the 5 aphid populations in this work, there did not appear to be development of any biotypes that would suggest a loss or reduction in the level of expression of aphid resistance in ICV-12. This was true even for locations where the cultivar is regularly cultivated, and where selections for aphid adaptation or overcoming plant resistance would presumably be likely.

However, because feeding and other behavioral characteristics were not directly investigated in this work, it is not possible to determine whether behavioral resistance exists in any of the test aphid populations. Also, dispersal behavior of A craccivora populations in Kenya, or in the Lake Victoria Basin of East Africa as a whole, needs to be studied to understand whether aphid populations in different locations are same subunits of a larger 

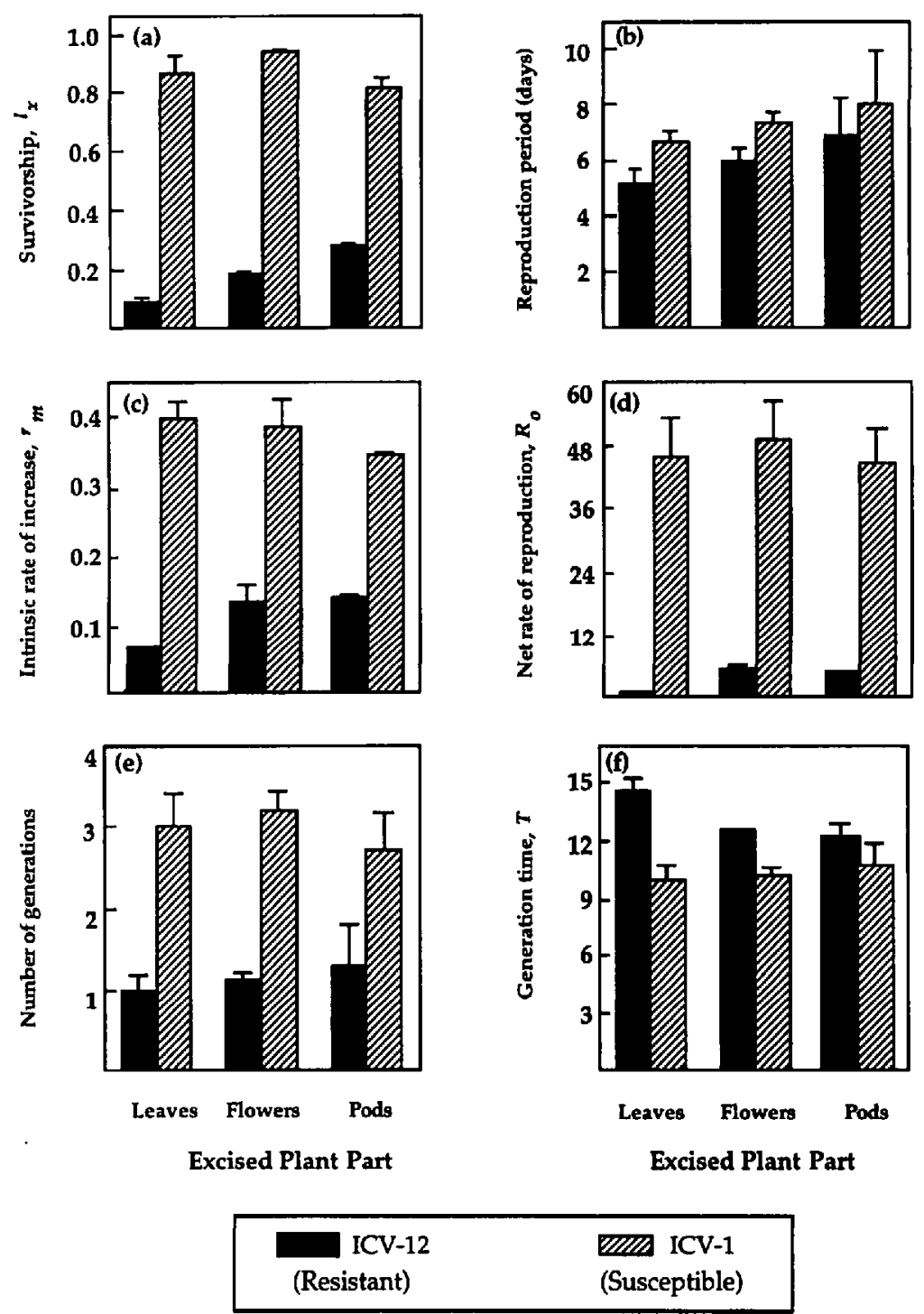

Fig. 1. Mean estimates of population parameters of MPFS aphid population on excised plant parts of aphidresistant (ICV-12) and aphid-susceptible (ICV-1) cowpea cultivars (a) survivorship, $l_{x}$; (b) reproductive period (days); (c) intrinsic rate of increase, $r_{m}$; (d) net rate of reproduction, $R_{0}$; (e) number of generations; (f) generation time, $T$ (means $+95 \% \mathrm{CI}, n=25$ ).

population or whether they are indeed entirely different populations, as was assumed in this work.

Excised tissues of ICV-12 plants also adversely affected survivorship and reproductive performance of the MPFS population. Similar to the trend observed in tests on whole plants, expression of plant resistance on aphid life table parameters on excised seedling leaves of ICV-12 were stronger than that observed for ICV-12. This suggests that injury to plants through excision did not alter the adverse effects of ICV-12 on aphid performance, contrary to observations by Givovich et al. (1988).

The measured parameters also provided good indications of ICV-12 resistance. Estimates of $l_{x}$, $r_{\mathrm{m}}$, and $R_{\mathrm{o}}$ provided clear differences between ef- fects of resistant and susceptible cultivars on $A$. craccivora performance. Thus, these studies confirm that survivorship and fecundity are key parameters for assessing cowpea resistance to $A$. craccivora. That trend was consistent with findings by Caillaud et al. (1995b) for S. avenae on wheat.

In summary, it is clear from this work that studies of life tables and population dynamics are useful tools in characterizing aphid resistance in cowpeas. Although this work did not find any differences among the different aphid populations, it is still useful to study variability in responses of different aphid populations for monitoring biotype development, and in evaluating the maintenance of plant resistance characteristics. 
Apart from host plant resistance, environmental factors (such as temperature) significantly affect aphid population dynamics (Elliott et al. 1988, Kocourek et al. 1994). Therefore, it is suggested that future studies should address interactions between important environmental factors and aphid resistance in cowpea cultivars.

\section{Acknowledgments}

We thank Charles Otuga Ouma, Silas Paul Ojwang, Cleophas Oduor, Peter Nyongessa, E. G. Kabiru, Festus Arum, and Pacifica Ogito for assistance in collection and establishment of aphid populations; Kailash Saxena, Edward Dwumfour, Samuel Firempong, Kwesi AmpongNyarko, Charles Mugoya, and Sam Kyamanwa for useful suggestions on the research; J. C. Olela and R. S. Pathak for supplying cowpea seeds used in the studies; and John Leeper and Francis Hsu for critical review of the manuscript. We also thank the First Presbyterian Church in Ithaca, Cornell Institute for African Studies and Center for International Studies, and the Rockefeller Foundation for financial support.

\section{References Cited}

Andrewartha, H. G., and L. C. Birch. 1954. The distribution and abundance of animals. University of Chicago Press, Chicago, IL.

Annan, I. B. 1992. Mechanisms of aphid resistance in cowpea and population dynamics of cowpea aphid Aphis craccivora Koch. Ph.D. dissertation, Comell University, Ithaca, NY.

Annan, I. B., K. N. Saxena, G. A. Schaefers, and W. M. Tingey. 1994. Effects of infestation by cowpea aphid (Homoptera: Aphididae) on different growth stages of resistant and susceptible cowpea cultivars. Insect Sci. Appl. 15: 401-410.

Annan, I. B., W. M. Tingey, G. A. Schaefers, and K. N. Saxena. 1996. Reproductive performance and population (Homoptera: Aphididae) on leaf extracts of resistant and susceptible cowpeas. J. Chem. Ecol. 22: 1345-1353.

Birch, L. C. 1948. The intrinsic rate of natural increase of an insect population. J. Anim. Ecol. 17: 1526.

Caillaud, C. M., C. A. Dedryver, J. P. Di Pietro, J. C. Simon, F. Fima, and B. Chaubet. 1995a. Clonal variability in the response of Sitobion avenae (Homoptera: Aphididae) to resistant and susceptible wheat. Bull. Entomol. Res. 85: 189-195.

Caillaud, C. M., J. S. Pierre, B. Chaubet, and J. P. Di Pietro. 1995b. Analysis of wheat resistance to the cereal aphid Sitobion avenae using electrical penetration graphs and flowcharts combined with correspondence analysis. Entomol. Exp. Appl. 75: 9-18.

Cartier, J. J. 1960. Growth, reproduction and longevity in one biotype of the pea aphid, Acyrthosiphon pisum (Harr.) (Homoptera: Aphididae). Can. Entomol. 92: 762-764.

1963. Varietal resistance of peas to pea aphid biotypes under field and greenhouse conditions. J. Econ. Entomol. 56: 205-213.

Elliott, N. C., R. W. Kieckhefer, and D. D. Walgenbach. 1988. Effects of constant and fluctuating temperatures on development rates and demographic statistics for the com leaf aphid (Homoptera: Aphididae). J. Econ. Entomol. 81: 1383-1389.

Firempong, S. 1988. Components of resistance to Aphis craccivora in some cowpea varieties. Entomol. Exp. Appl. 48: 241-246.

Givovich, A., J. Weibull, and J. Pettersson. 1988. Cowpea aphid performance and behavior on two resistant cowpea lines. Entomol. Exp. Appl. 49: 259264.

Kocourek, F., J. Havelka, J. Beránková, and V. Jarosik. 1994. Effect of temperature on development rate and intrinsic rate of increase of Aphis gossypii reared on greenhouse cucumbers. Entomol. Exp. Appl. 71: 59-64.

MacFoy, C.C.A., and Z. T. Dabrowski. 1984. Preliminary studies on cowpea resistance to Aphis craccivora Koch (Homoptera: Aphididae). Z. Angew. Entomol 97: 202-209.

Messina, F. J., J.A.A. Renwick, and J. L. Barmore. 1985. Resistance to Aphis craccivora (Homoptera: Apididae) in selected varieties of cowpea. J. Entomol. Sci. 20: 263-269.

Niassy, A., J. D. Ryan, and D. C. Peters. 1987. Variations in feeding behavior, fecundity, and damage of biotypes $\mathrm{B}$ and $\mathbf{E}$ of Schizaphis graminum (Homoptera: Aphididae) on three wheat genotypes. Environ. Entomol. 16: 1163-1168.

Ofuya, T. I. 1988a. Antibiosis in some cowpea varieties resistant to the cowpea aphid, Aphis craccivora Koch (Homoptera: Aphididae). Int. Pest Control 30: 68-69

1988b. Varietal resistance of cowpeas to the cowpea aphid, Aphis craccivora Koch (Homoptera: Aphididae) under field and screenhouse conditions in $\mathrm{Ni}$ geria. Trop. Pest Manage. 34: 445-447.

1989. The effect of pod growth stages in cowpea on aphid reproduction and damage by the cowpea aphid, Aphis craccivora (Homoptera: Aphididae). Ann. Appl. Biol. 15: 563-566.

1993. Evaluation of selected cowpea varieties for resistance to Aphis craccivora Koch (Homoptera: Aphididae) at the seedling and podding phase. Ann. Appl. Biol. 123: 19-23.

Painter, R. H. 1951. Insect resistance in crop plants. Macmillan, New York.

Pathak, R. S. 1988. Genetics of resistance to aphid in cowpea. Crop Sci. 28: 474-476.

Pathak, R. S., and J. C. Olela. 1986. Registration of 14 cowpea cultivars. Crop Sci. 26: 647-648.

SAS Institute. 1988. SAS/STAT user's guide, release 6.03 ed. SAS Institute, Cary, NC.

Singh, S. R., H. F. van Emden, and T. A. Taylor [eds.]. 1978. Pests of grain legumes: ecology and control. Academic, New York.

Singh, S. R., and K. O. Rachie [eds.]. 1985. Cowpea research, production and utilization. Wiley, New York.

Snedecor, G. W., and W.G. Cochran. 1980. Statistical methods, 7th ed. Iowa State University Press, Ames.

Southwood, T.R.E. 1978. Ecological methods with particular reference to the study of insect populations, 2nd ed. Chapman \& Hall, London.

Tingey, W. M. 1986. Techniques for evaluating plant resistance to insects, pp. 251-284. In J. R. Miller and T. A. Miller [eds.], Insect-plant interactions. Ser. Exp. Entomol. Springer, New York.

Received for publication 19 April 1996; accepted 15 November 1996 . 